\title{
Sustainable EOQ Model with Multi Container Transportation Problems
}

\author{
Ahmad Mubin ${ }^{a^{*}}$, Fahmi Syahril a, Tyas Yuli Rosiani b \\ a Department of Industrial Engineering, Universitas Muhammadiyah Malang, Malang, Indonesia \\ ${ }^{\mathrm{b}}$ Department of Industrial Management National Formosa University, Taiwan \\ *Correspondence Author: ahmadm@umm.ac.id
}

\section{ARTICLE INFO}

Article history

Received May 30, 2021

Revised August 18, 2021

Accepted August 27, 2021

Available Online August 31, 2021

Keywords

Carbon emission

Sustainable EOQ

Multi Container

Transportation

\begin{abstract}
Industrial developments and environmental problems encourage decision-makers to determine optimal decisions. In addition, transportation is an aspect that has a significant contribution to environmental damage. Therefore, inventory and transportation decisions need to be integrated to minimize environmental problems. This study made an effort to develop a model of Sustainable EOQ with Multi Container Transportation Problems. The optimal procedure was proposed to determine the optimal number of containers in one vehicle. The results suggested that the proposed procedure could minimize the total annual inventory cost compared to the company's current solution.
\end{abstract}

This is an open-access article under the CC-BY-SA license.

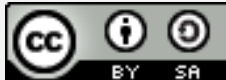

\section{Introduction}

Due to the importance of sustainable development, leading researchers and organizations are increasingly paying attention to Sustainable Supply Chain Management (SSCM) as a new paradigm [1,2]. SSCM is also a new concept in operations management. One of the exciting topics in SSCM and operations management is inventory management $[3,4]$. Previous researchers have been interested in discussing Economic Order Quantity (EOQ) [5] and Economic Production Quantity (EPQ) [6, 7] as essential areas of operations management for more than a century. As the inspiration for the inventory problem, Harris [5] offers the optimal lot size determined by the trade-off between holding and order costs. The order lot size directly impacts the economic and environmental performance of the production system [8]. Therefore, the growing concern about environmental issues emphasizes the importance of treating inventory management decisions with care $[9,10]$.

Many researchers have exercised to model the problem of sustainable lot size for various supply chain channels [11-13]. In a defective manufacturing system with auction and reworking, Nobil and Taleizadeh [14] formulated a single-machine multi-item EPQ problem. Jana, et al. [15] used a geometric programming technique to solve a fuzzy multiitem EPQ model that took into account the shortcomings and reliability of the process. Mishra, et al. [16] investigated the issue of EPQ under tax regulations and carbon caps, taking into account controllable carbon emissions and supply shortages. Rossi, et al. [17] proposed a new method for modeling a single machine multi-product EOQ problem with capacity constraints in a particular inventory/production system. Rabta [18] proposed an 
EOQ model that considered the linear or nonlinear relationship between product demand, price, and cost. Hasan, et al. [19] also developed a new model for co-investment technology and determining inventory levels using a cap and trade approach and a carbon tax, taking carbon emissions into account. Mishra, et al. [20] proposed a sustainable inventory model that resembled inventory reductions and reordering, as well as price-dependent demand and control carbon emissions.

In addition, the problem of transportation becomes a problem under inventory management. Several inventory models have involved transportation costs proposed by Swenseth and Godfrey [21]. Ertogral, et al. [22] developed a transportation cost model determined by the mode of transportation used and the size of the shipment. Furthermore, the use of various vehicles was considered in the study of Zhao, et al. [23]. In the study of sustainable EOQ with transportation, several studies have been published. Lee, et al. [24] offered a sustainable EOQ model under lead-time uncertainty and multi-modal transport. A model considering partial back-ordering and involving transportation emission cost reduction was proposed by Lin [25]. Bouchery, et al. [26] suggested a multi-objective model of sustainable transportation and order quantity. The model involving Transportation, Warehouse, Emission Carbon Costs, and Capacity Limits was proposed by Utama, et al. [27].

Based on this description, the sustainable EOQ model involving transportation problems is still inadequate. This study tried to develop a sustainable EOQ model with Multi Container Transportation Problems. This research model was developed from research conducted by Utama, et al. [27]. In the previous model, they did not consider the number of containers transported. Therefore, this study was intended to develop a sustainable EOQ model by considering the container being transported. The proposed research model was based on case studies in companies in Indonesia. This research contributes to the development of knowledge in inventory by proposing a sustainable EOQ model that considers the multi-container problem. In addition, this research provides solutions for companies to inventory decisions.

\section{Methods}

\subsection{Assumption and Notations}

The assumptions used in the sustainable EOQ model are (1) demand, and product prices are deterministic, and (2) costs are fixed. The notations used in the sustainable EOQ model are as follows:

\begin{tabular}{|c|c|}
\hline$D$ & : annual request [units/year] \\
\hline$u$ & : purchase cost [IDR/unit $]$ \\
\hline$t$ & : disability cost $[I D R /$ unit $]$ \\
\hline$b$ & : space occupied by a product unit $\left[\mathrm{m}^{3} /\right.$ ton $]$ \\
\hline$a$ & : unit weight stored in a warehouse [ton/ unit] \\
\hline$o$ & : order cost [IDR /order $]$ \\
\hline$h$ & : holding cost [IDR / unit $]$ \\
\hline$e$ & : average carbon emission in a warehouse $\left[I D R / \mathrm{m}^{3}\right]$ \\
\hline$l$ & : percent average annual disability [\%] \\
\hline$j$ & : average cost of carbon emissions for storage and disability [IDR/ton] \\
\hline$d$ & : transportation trip distance to vendor $[\mathrm{km}]$ \\
\hline$n$ & : number of containers that can be transported in 1 vehicle [units] \\
\hline$y$ & : container capacity that can be transported [units] \\
\hline
\end{tabular}


$k \quad$ : range of order quantity $\mathrm{Qs}$ between the two discontinuity points $D P k$ and $D P k+1$

$D P k \quad$ : the point of discontinuity for the range $\mathrm{k}$, defined as $\sum n * y$

$i \quad$ : fixed internal cost of transportation $[I D R / \mathrm{km}]$

$v \quad:$ internal cost variable in transporter $\left[I D R / \mathrm{km} \mathrm{m}^{3}\right]$

$x \quad$ : fixed external cost in transporter $[I D R / \mathrm{km}]$

$w \quad$ : external cost variable in transporter $\left[I D R / \mathrm{km} \mathrm{m}^{3}\right]$

\subsection{EOQ Sustainable Mathematical Model}

This section discusses the mathematical model in the proposed sustainable EOQ model. The total cost of the research inventory implemented the five (5) cost components: total annual purchase costs, annual order costs, annual inventory costs, obsolescence costs, and transportation costs. The total annual cost is formulated in Equation (1).

$$
C s=u \cdot D+\operatorname{Co}(Q)+\operatorname{Ch}(Q)+\operatorname{Cobs}(Q)+\operatorname{Ct}(Q)
$$

The purchase cost was based on the total demand (D) multiplied by the product price per unit (1). For annual order costs, this cost component was modeled in Equation (2). Furthermore, the annual inventory cost was modeled in Equation (3). The annual inventory cost model considered the holding costs, average carbon emissions in warehouses, and space occupied by a product unit.

$$
\begin{aligned}
& \operatorname{Co}(Q)=\frac{D \cdot o}{Q} \\
& \operatorname{Ch}(Q)=\frac{Q}{2} \cdot h \cdot e \cdot b
\end{aligned}
$$

Inventories in the warehouse had obsolescence risk at the end of the year, which was measured by an annual obsolescence risk level of $l$. The obsolescence product was sold by the buyer to a particular waste treatment company for disposal for $t$. This problem was modeled in Equation (4).

$$
\operatorname{Cobs}(Q)=\frac{Q}{2} \cdot l \cdot((u-t) \cdot a \cdot j)
$$

In addition, this study also proposed transportation costs based on the number of containers transported by vehicles. The total annual transportation costs considered internal and external transportation costs, distance, and space for each product. This transportation design was modeled in Equation (5).

$$
C t=\frac{[(i+x) \cdot d \cdot n+(v+w) b \cdot d \cdot D P k](D)}{Q}
$$

Based on the cost components described above, the annual total inventory cost of the sustainable EOQ model was presented in Equation (6).

$$
C s=u \cdot D+\frac{D \cdot o}{Q}+\frac{Q}{2} \cdot h \cdot e \cdot b+\frac{Q}{2} \cdot l \cdot((u-t) \cdot a \cdot j)+\frac{[(i+x) \cdot d \cdot n+(v+w) b \cdot d \cdot D P k](D)}{Q}
$$

To produce the optimal quantity $\mathrm{Q}$ on $D P k$, the annual total inventory cost shown in Equation (6) was the first differential to $Q$. Then, the optimal $Q$ value calculated for each $D P k$ was presented in Equation (7). 


$$
Q=\frac{\sqrt{2} \sqrt{D} \sqrt{D P k . b . d . v+D P k . b . d . w+d . i . n+d . n . x+o}}{\sqrt{a . j . l+h . e . b-l . t+l . u}}
$$

\subsection{Problem Solving Steps}

In this section, the optimum total inventory cost was calculated using the procedure developed by Zhao, et al. [23]. Details of the optimization steps are organized as follows:

$$
Q^{` k}=\frac{\sqrt{2} \sqrt{D} \sqrt{D \text { Pk.b.d.v+DPk.b.d.w+d.i.n+d.n.x+o }}}{\sqrt{\text { a.j.l+h.e.b-l.t+l.u}}}
$$

Step 1: Determine the $k-t h$ ranges that are feasible for each value of $k$ with Equation (8).

Step 2: $\quad$ In each $\mathrm{k}$ range, the optimal $Q^{{ }^{k *}}$ can be calculated as:

$$
\begin{aligned}
& Q^{k *}=Q^{k *} \text { when } D P k<Q^{k *} \leq D P k+1 \text { or } \\
& Q^{k *}=D P k \text { when } C s(D P k) \leq C s(D P k+1) \text { or } \\
& Q^{k *}=D P k+1 \text { when } C s(D P k)>C s(D P k+1) .
\end{aligned}
$$

Step 3: The minimum total cost $\mathrm{Cs}(\mathrm{EOQ})$ is defined as the minimum between the local total minimum cost values $C s\left(Q^{k *}\right)$ as $C s(E O Q)=\min C s\left(Q^{k *}\right)$ for all $k$ ranges. $E O Q=$ $Q^{k *}$ which satisfies the Equation of $C s(E O Q)=\min C s\left(Q^{k *}\right)$.

\subsection{Research Data}

The data of this research were based on case studies on companies in Indonesia. The research data are presented in Table 1 . In this problem, the $k$ range (transported container) was set from 1 to 8 . The company used one vehicle for transportation. For each transportation activity, the company decided to transport eight containers with a total quantity of 8000 .

Table 1. Research Data

\begin{tabular}{ll}
\hline Variable & Value \\
$D$ & 40,260 Unit \\
\hline$u$ & Rp. 240,000 \\
\hline$t$ & Rp. 55,000 \\
\hline$b$ & $0.0756 \mathrm{~m}^{3}$ \\
\hline$a$ & $0.05 /$ Unit \\
\hline$o$ & Rp. $1,250,000$ \\
\hline$h$ & Rp. 3,000 \\
\hline$e$ & Rp. 15,000 \\
\hline$l$ & $8 \%$ \\
\hline$j$ & Rp. 30,000 \\
\hline$d$ & $121 \mathrm{Km}$ \\
\hline$y$ & 1 ton Per container \\
\hline$x$ & 8 ton \\
\hline$w$ & Rp. 145,000 \\
\hline & Rp. 54,000
\end{tabular}

This study also analyzed sensitivity to several variables such as fixed external cost, external cost variable, and distance. The effect of these variables was tested for their effect 
on the total cost of inventory. All research data processing was carried out with the help of Maple 17 software.

\section{Results and Discussion}

\subsection{Model Optimization}

The optimization results based on the proposed optimization procedure are shown in Table 1. The results indicated that the optimal total inventory cost for each $n, D P k$, $D P k+1$ was to use six containers. The resulting optimal total cost was $D P k+1$ with a total inventory cost of IDR 298,506,517. Furthermore, the result was more optimal than the current firm's quantity decisions. As a result, the company's current total annual inventory cost was IDR 303,385,166. The total annual inventory cost comparison between the company's proposals and decisions is shown in Fig. 1.

Table 2. Optimization results based on the proposed optimization procedure

\begin{tabular}{lllllllr}
\hline$n$ & \multicolumn{1}{c}{$D P k$} & $D P k+1$ & $Q^{k^{*}}$ & $\begin{array}{l}D P k<Q^{k *} \\
\leq D P k+1\end{array}$ & $C s\left(Q^{k^{*}}, \operatorname{Cs}(D P k)(\mathrm{Rp})\right.$ & $\begin{array}{l}C s(D P k+1) \\
(\mathrm{Rp})\end{array}$ \\
\hline 1 & 1 & 1000 & 47.584 & FALSE & - & $20,653,597,410$ & $310,222,237$ \\
\hline 2 & 1001 & 2000 & 66.144 & FALSE & - & $501,626,292$ & $303,002,265$ \\
\hline 3 & 2001 & 3000 & 80.534 & FALSE & - & $398,755,823$ & $300,659,121$ \\
\hline 4 & 3001 & 4000 & 92.719 & FALSE & - & $364,506,306$ & $299,535,184$ \\
\hline 5 & 4001 & 5000 & 103.480 & FALSE & - & $347,424,891$ & $298,898,930$ \\
\hline 6 & 5001 & 6000 & 113.220 & FALSE & - & $337,212,776$ & $\mathbf{2 9 8 , 5 0 6 , 5 1 7}$ \\
\hline 7 & 6001 & 7000 & 123.690 & FALSE & - & $337,498,323$ & $303,298,883$ \\
\hline 8 & 7001 & 8000 & 132.230 & FALSE & - & $332,684,793$ & $303,385,166$ \\
\hline
\end{tabular}

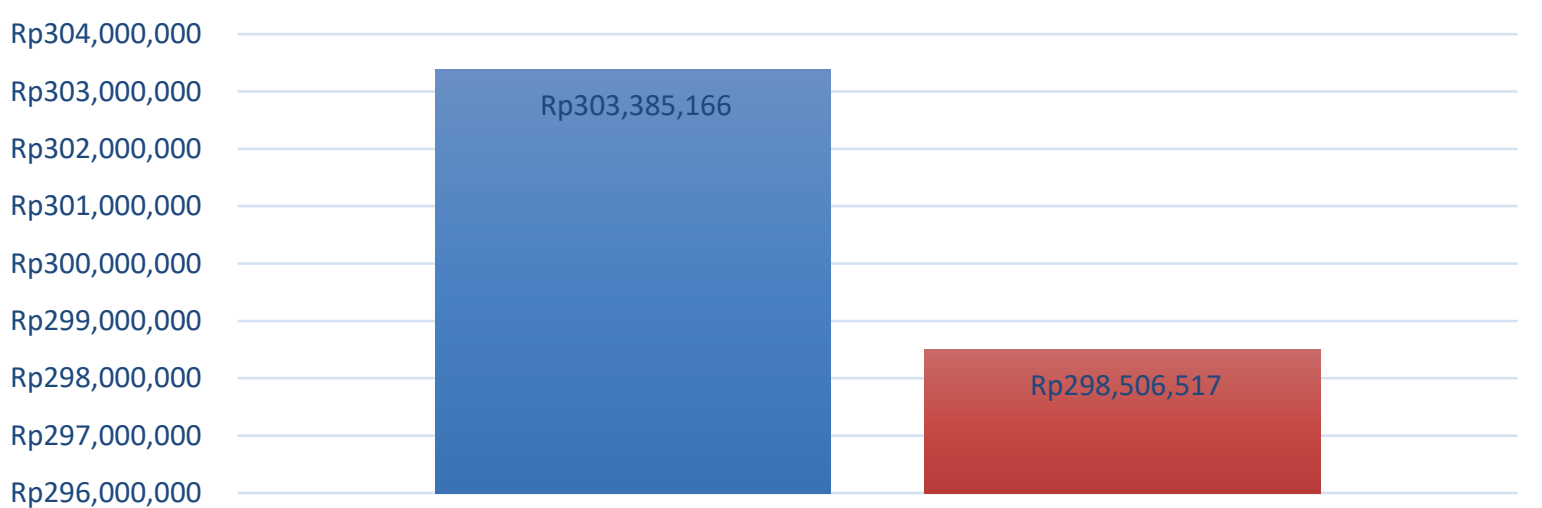

Rp296,000,000

- total annual inventory cost existing $\quad$ total annual inventory cost based on proposed method

Fig. 1. Comparison of total annual inventory cost

\subsection{Sensitivity Analysis}

The effect of changes in fixed external costs $(x)$ on total annual inventory costs $(C s)$ is presented in Fig. 2. Eleven (11) experiments were conducted from the fixed external cost range of IDR 120,000 to IDR 170,000. Based on the experiment, research results suggested that the higher the fixed external cost $(x)$, the higher the total annual inventory cost $(C s)$. On the other hand, the lower the fixed external cost (x), the lower the total annual inventory cost $(C s)$. 


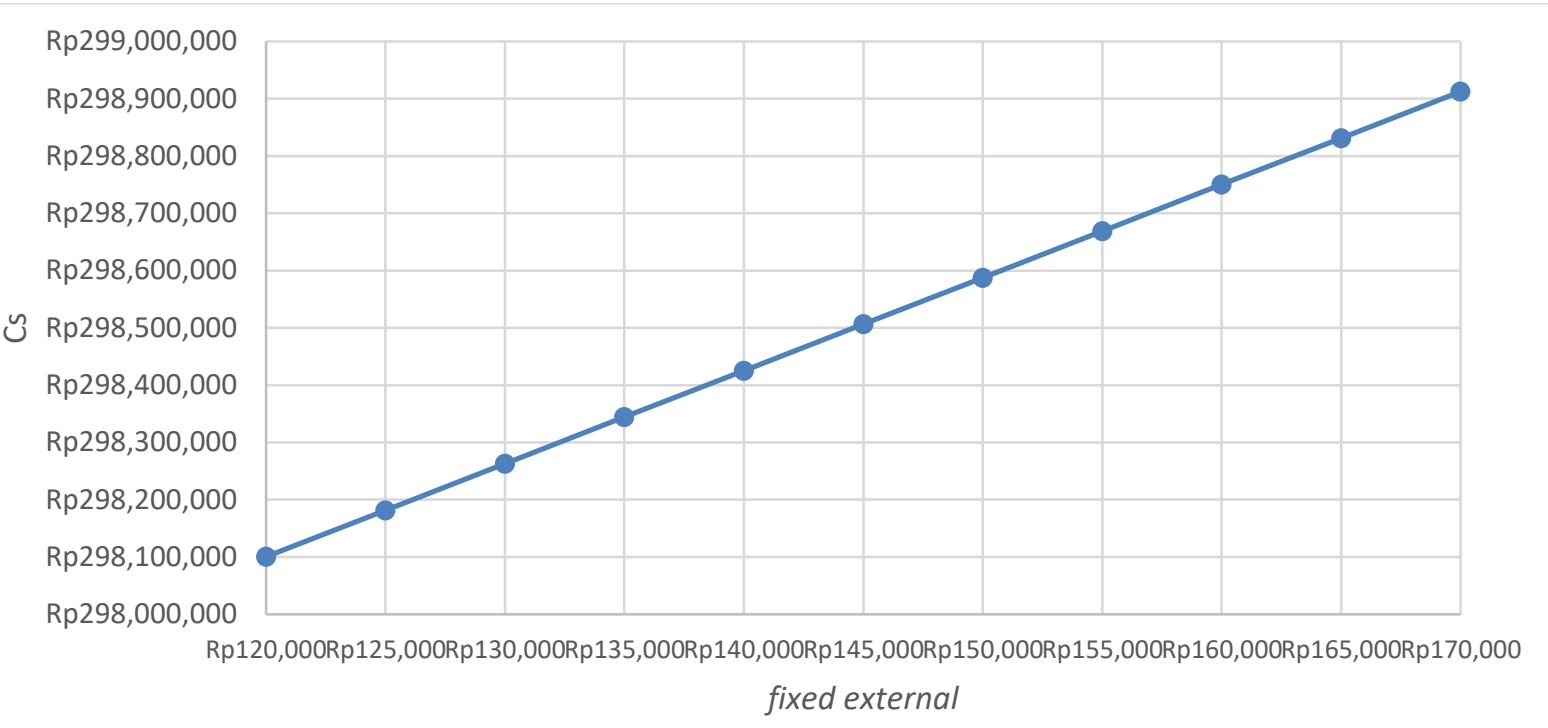

Fig. 2. Effect of changes in fixed external costs (x) on total annual inventory costs (Cs)

The effect of changes in external variable costs $(w)$ on total annual inventory costs $(C s)$ is presented in FiFig. 3. Eleven (11) experiments were administered from the fixed external cost range of IDR 29,000 to IDR 79,000. Based on the experiment, the results projected that the higher the external variable cost $(w)$, the higher the total annual inventory cost $(C s)$. On the other hand, the lower the external variable cost $(w)$, the lower the total annual inventory cost $(C s)$.

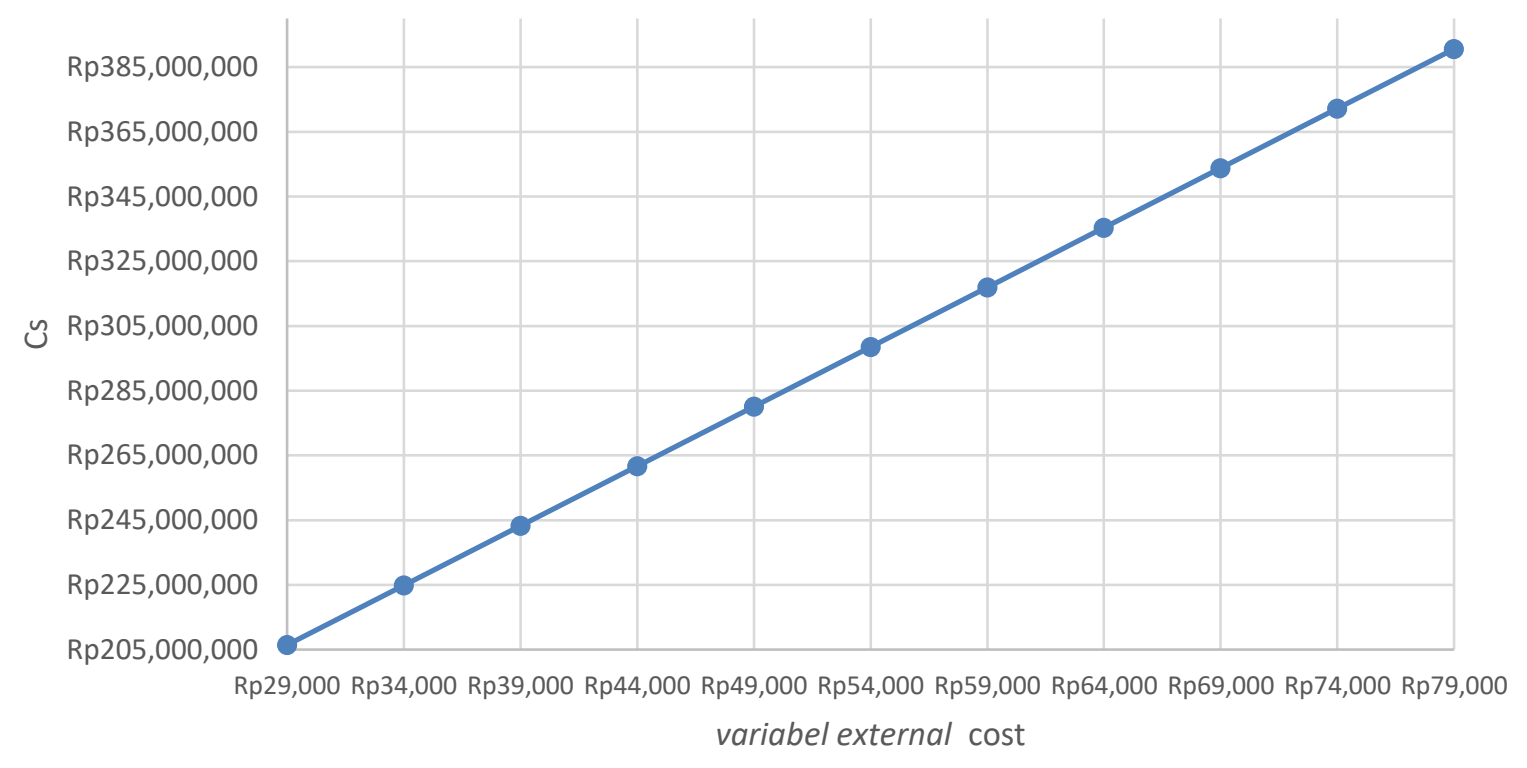

Fig. 3. Effect of changes in external variable costs on total annual inventory costs (Cs) 


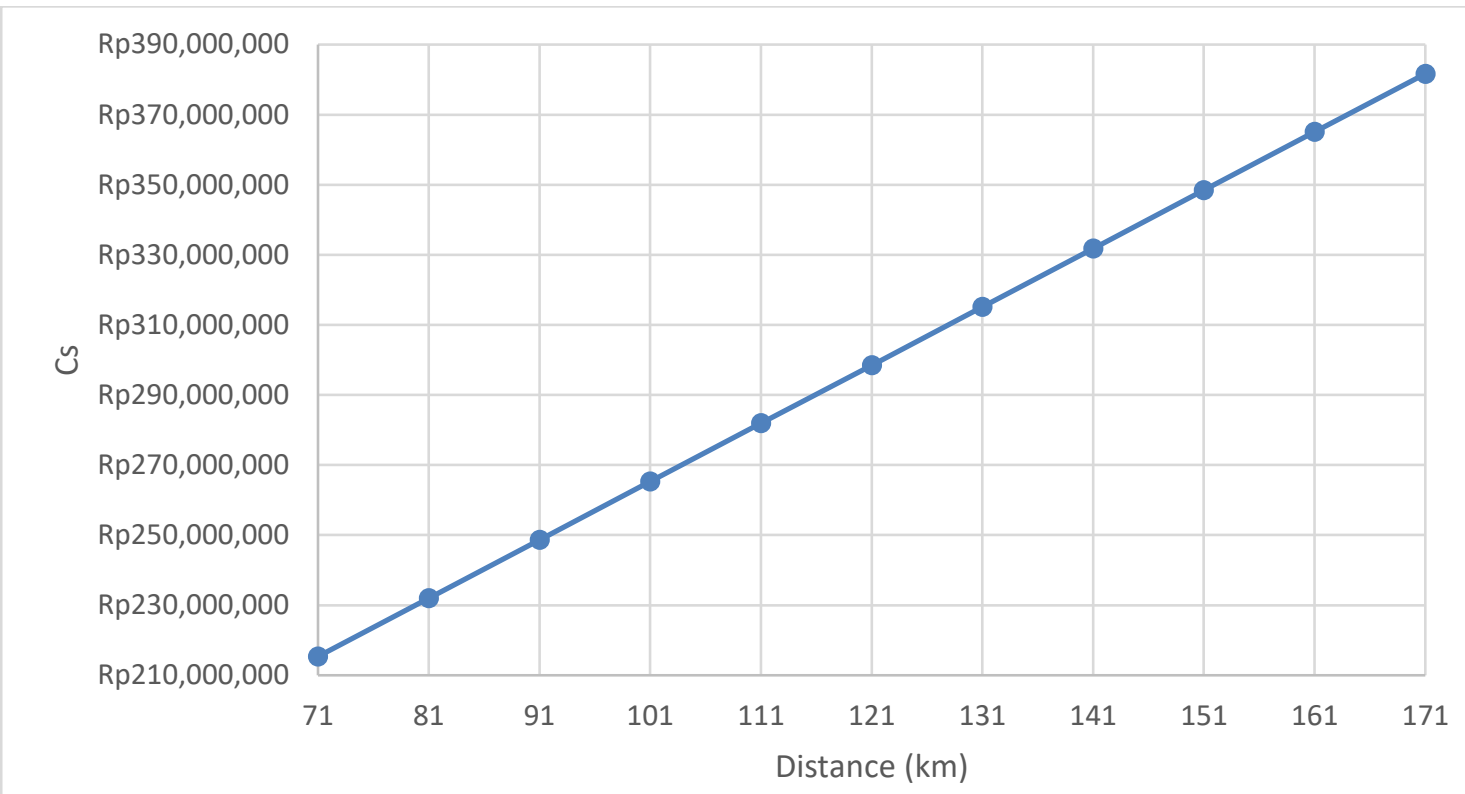

Fig. 4. Effect of distance on total annual inventory cost $(\mathrm{Cs})$

The effect of distance on the total annual inventory cost $(C s)$ is presented in Fig. 4. From the Figure, it was stated that vehicle distance affected transportation costs and total annual inventory costs. The smaller the distance, it was directly proportional to the transportation costs and total inventory costs.

\section{Conclusion}

This study made an effort to develop a sustainable EOQ model by considering Multi Container Transportation Problems. A solution optimization procedure was presented to minimize the total annual inventory cost. The results showed that the proposed procedure was able to minimize the total annual inventory cost. In addition, a sensitivity analysis was also presented. This study has limitations, including assuming unlimited warehouse capacity. Further research needs to consider warehouse capacity in solving sustainable EOQ problems.

\section{Data Availability}

All data generated or analyzed during this study are included in this article.

\section{Declarations}

Author contribution: All authors contributed equally to the main contributor to this paper. In addition, all authors read and approved the final paper.

Funding statement: No funding was received for this study.

Conflict of interest: The authors declare no conflict of interest.

Additional information: No additional information is available for this paper.

\section{Acknowledgment}

We thank the anonymous reviewers for their careful reading of our paper and their many insightful comments and suggestions. 


\section{References}

[1] M. F. Ibrahim, M. M. Putri, and D. M. Utama, "A literature review on reducing carbon emission from supply chain system: drivers, barriers, performance indicators, and practices," IOP Conference Series: Materials Science and Engineering, vol. 722, p. 012034, 2020. http://doi.org/10.1088/1757-899x/722/1/012034.

[2] A. Agustiandi, Y. M. K. Aritonang, and C. Rikardo, "Integrated Inventory Model for Single Vendor Multi-Buyer with a Single Item by Considering Warehouse and Capital Constraint," Jurnal Teknik Industri, vol. 22, no. 1, pp. 71-84, 2021. http://doi.org/10.22219/JTIUMM.Vol22.No1.71-84.

[3] S. Mitra, "Inventory management in a two-echelon closed-loop supply chain with correlated demands and returns," Computers \& Industrial Engineering, vol. 62, no. 4, pp. 870-879, 2012. https://doi.org/10.1016/j.cie.2011.12.008.

[4] D. M. Utama, H. M. Kholik, and A. F. Mulya, "Integrated Procurement-Production Inventory Model with Two-Stage Production," Jurnal Teknik Industri, vol. 21, no. 2, pp. 185-199, 2020. http://doi.org/10.22219/JTIUMM.Vol21.No2.185-199.

[5] F. W. Harris, "How many parts to make at once," The Magazine of Management, vol. 10, pp. 135-136, 1913.

[6] E. Taft, "The most economical production lot," Iron Age, vol. 101, no. 18, pp. 1410$1412,1918$.

[7] D. M. Utama, D. P. Wardani, S. T. Halifah, and D. C. Pradikta, "Model Economic Production Quantity dengan Rework Process dan Batasan Gudang," Jurnal Sistem dan Manajemen Industri, vol. 3, no. 1, pp. 43-49, 2019. http://doi.org/10.30656/jsmi.v3i1.1017.

[8] M. Bonney and M. Y. Jaber, "Environmentally responsible inventory models: Nonclassical models for a non-classical era," International Journal of Production Economics, vol. 133, no. 1, pp. 43-53, 2011. https://doi.org/10.1016/j.ijpe.2009.10.033.

[9] D. S. Widodo and D. M. Utama, "Analisis Model Sustainable Economic Order Quantity Dengan Mempertimbangkan Emisi Karbon Dan Batasan Kapasitas Gudang Untuk Menekan Total Biaya Persediaan," Teknik, vol. 40, no. 3, pp. 169175, 2019. http://doi.org/10.14710/teknik.v40i3.24508.

[10] S. K. D. B. Maulana et al., "The Capacitated Sustainable EOQ Models: Models Considering Tax Emissions," vol. 21, no. 1, pp. 12-21, 2020. https://doi.org/10.22219/JTIUMM.Vol21.No1.12-21.

[11] T. Abdallah, A. Diabat, and D. Simchi-Levi, "Sustainable supply chain design: a closed-loop formulation and sensitivity analysis," Production Planning \& Control, vol. 23, no. 2-3, pp. 120-133, 2012. http://doi.org/10.1080/09537287.2011.591622.

[12] A. Gurtu, M. Y. Jaber, and C. Searcy, "Impact of fuel price and emissions on inventory policies," Applied Mathematical Modelling, vol. 39, no. 3, pp. 1202-1216, 2015. https://doi.org/10.1016/j.apm.2014.08.001.

[13] R. Hammami, I. Nouira, and Y. Frein, "Carbon emissions in a multi-echelon production-inventory model with lead time constraints," International Journal of Production Economics, vol. 164, pp. 292-307, 2015. https://doi.org/10.1016/j.ijpe.2014.12.017.

[14] A. H. Nobil and A. A. Taleizadeh, "A single machine EPQ inventory model for a multi-product imperfect production system with rework process and auction," International Journal of Advanced Logistics, vol. 5, no. 3-4, pp. 141-152, 2016. http://doi.org/10.1080/2287108X.2016.1207975. 
[15] D. K. Jana, K. Maity, and T. K. Roy, "Multi-item production inventory model with fuzzy rough coefficients via geometric programming approach," Opsearch, vol. 50, no. 4, pp. 475-490, 2013. http://doi.org/10.1007/s12597-013-0122-9.

[16] U. Mishra, J.-Z. Wu, and B. Sarkar, "A sustainable production-inventory model for a controllable carbon emissions rate under shortages," Journal of Cleaner Production, vol. 256, p. 120268, 2020. https://doi.org/10.1016/j.jclepro.2020.120268.

[17] T. Rossi, R. Pozzi, and M. Testa, "EOQ-based inventory management in singlemachine multi-item systems," Omega, vol. 71, pp. 106-113, 2017. https://doi.org/10.1016/j.omega.2016.10.002.

[18] B. Rabta, "An Economic Order Quantity inventory model for a product with a circular economy indicator," Computers \& Industrial Engineering, vol. 140, p. 106215, 2020. https://doi.org/10.1016/j.cie.2019.106215.

[19] M. R. Hasan, T. C. Roy, Y. Daryanto, and H.-M. Wee, "Optimizing inventory level and technology investment under a carbon tax, cap-and-trade and strict carbon limit regulations," Sustainable Production and Consumption, vol. 25, pp. 604-621, 2021. https://doi.org/10.1016/j.spc.2020.12.005.

[20] U. Mishra, J.-Z. Wu, and M.-L. Tseng, "Effects of a hybrid-price-stock dependent demand on the optimal solutions of a deteriorating inventory system and trade credit policy on re-manufactured product," Journal of Cleaner Production, vol. 241, p. 118282, 2019. https://doi.org/10.1016/j.jclepro.2019.118282.

[21] S. R. Swenseth and M. R. Godfrey, "Incorporating transportation costs into inventory replenishment decisions," International Journal of Production Economics, vol. 77, no. 2, pp. 113-130, 2002. https://doi.org/10.1016/S0925-5273(01)00230-4.

[22] K. Ertogral, M. Darwish, and M. Ben-Daya, "Production and shipment lot sizing in a vendor-buyer supply chain with transportation cost," European Journal of Operational Research, vol. 176, no. 3, pp. 1592-1606, 2007. https://doi.org/10.1016/j.ejor.2005.10.036.

[23] Q.-H. Zhao, S.-Y. Wang, K. K. Lai, and G.-P. Xia, "Model and algorithm of an inventory problem with the consideration of transportation cost," Computers \& Industrial Engineering, vol. 46, no. 2, pp. 389-397, 2004. https://doi.org/10.1016/j.cie.2003.12.019.

[24] S.-K. Lee, S. H. Yoo, and T. Cheong, "Sustainable EOQ under Lead-Time Uncertainty and Multi-Modal Transport," Sustainability, vol. 9, no. 3, 2017. http://doi.org/10.3390/su9030476.

[25] H.-J. Lin, "Investing in Transportation Emission Cost Reduction on Environmentally Sustainable EOQ Models with Partial Backordering," Journal of Applied Science and Engineering, vol. 21, no. 3, pp. 291-303, 2018. http://doi.org/10.6180/jase.201809_21(3).0001.

[26] Y. Bouchery, A. Ghaffari, Z. Jemai, and J. Fransoo, "Sustainable transportation and order quantity: insights from multi-objective optimization," Flexible Services and Manufacturing Journal, vol. 28, no. 3, pp. 367-396, 2016. http://doi.org/10.1007/s10696-016-9240-z.

[27] D. M. Utama, D. S. Widodo, M. F. Ibrahim, K. Hidayat, and S. K. Dewi, "The Sustainable Economic Order Quantity Model: A Model Consider Transportation, Warehouse, Emission Carbon Costs, and Capacity Limits," Journal of Physics: Conference Series, vol. 1569, pp. 022095, 2020. http://doi.org/10.1088/1742$6596 / 1569 / 2 / 022095$. 